\title{
Evaluation of the Use of Some Benthic Macro-invertebrate Multimetric Indices Associations with Environmental Variables in Ecological Assessment of Some Ethiopian Rivers
}

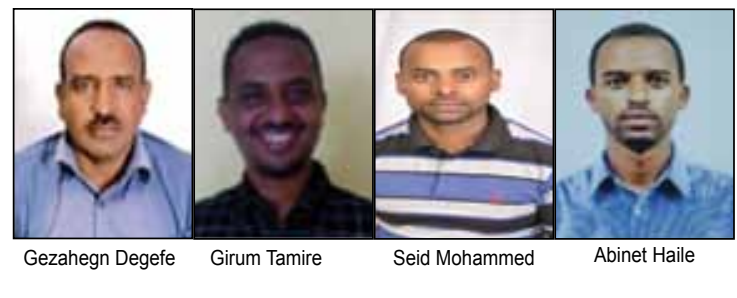

\section{Gezahegn Degefe, Girum Tamire, Seid Mohammed and Abinet Haile}

Abstract: The ecological status of six selected rivers which are found around central Ethiopia and North Shewa Zone and exposed to environmental stresses at varied extent, was studied using biological quality elements (BQE). One thousand one hundred thirty three (1133) individuals of macroinvertebrates, from 22 families and 5 orders of insects, were collected from the rivers. Seven metrics that had low correlation $(p>0.05)$ were selected to calculate the final B-IBI and the result showed that both sites of Akaki, Sebeta and Jemma Rivers had poor water quality whereas Beresa, Chacha and Mojo (upstream site) had relatively better water quality. Canonical Correspondence Analysis (CCA) showed that Tabanidae, Syrphidae, Culicidae, and Canidae was more strongly correlated with temperature but strongly and negatively with $\mathrm{pH}$, Dissolve Oxygen (DO) and Nitrate. The result implied that the change in abundance of these groups of macroinvertebrates could indicate the change in $\mathrm{pH}$, DO and Nitrate. $\mathrm{pH}$ and DO were significantly $(\mathrm{p}<0.05)$ and positively correlated with \% Ephemeroptera and $\%$ Baetidae. On the other hand, DO showed strong but negative correlation \% Oligochaeta, \% Non-Insect and Hillsenhoff Family Biotic Index which implied that that the change in $\mathrm{pH}$ and level of organic pollution can be easily monitored using these metrics

Keywords: Benthic macro invertebrates, Biotic Metrics, Water quality

\section{Introduction}

$\mathbf{R}$ ivers and streams provide water for domestic uses, Ragriculture, transport, industries, power production and recreation for humans. However, the ecosystems of many rivers and streams have been considerably affected globally with the growth of human population, agricultural activities, urbanization and industrial development. The main impacts of such changes are loss of habitat and excessive addition of pollutants into the nearby water bodies, which in turn causes severe water pollution (Velho et al 2005). The health of streams and rivers can be influenced, not only by anthropogenic factors, but also by geomorphologic characteristics, hydrological, chemical and physical aspects of water quality (Davis and Day, 1998).

In Ethiopia, a considerable amount of waste ends up in drainage system, threatening both surface water and ground water quality. The problem is more pronounced in the central part of Ethiopia where increase in human population and industrial growth is more pronounced (Beneberu, 2013; Eshetu, 2012) and it calls urgent monitoring intervention by concerned governmental and non-governmental bodies. Prior to devising well defined strategies to manage aquatic ecosystems of Ethiopia, it is imperative to know the current status of aquatic water resource of the country using appropriate and integrated methods.

Physical and chemical parameters have been used as water quality indicators for many years in many countries (Valentina et al 2011). However, scientists are turning their attention to the use of biological quality elements (BQE) or biological multimetric indices in monitoring studies because the traditional methods (physical and chemical methods) are quiet expensive and required well-trained expertise (Valentina et al 2011). Macro invertebrates are the most commonly used among BQE in monitoring studies as they are very sensitive to water status changes (Moorse et al 2007). One of the easiest means to assess whether pollution is causing severe ecological impact in a particular aquatic system is by analyzing the community structures of macroinvertebrate and comparing the results with those found in pristine habitat using multimetric indices (Pawlak, 1999). Multimetric indices are being used commonly as they show complex biological data and produce relevant information for regulatory agencies and decision makers (Karr and Chu 1999). However, the character and ecological preference of many macroinvertebrate families is yet to be discovered. Therefore, studies regarding the association between macroinvertebrates and their localized environmental features are vital to identify the power of macroinvertebrates to indicate the ecological status of riverine ecosystems.

\section{Materials and Methods}

\section{Study Sites}

The study was conducted on six rivers and twelve sites (Fig 1). Three of the rivers (Akaki, Sebeta and Mojo) are part of the Awash basin with relatively low altitude (1600-2250m). These rivers have been and are being severely impacted for many years by anthropogenic impacts mainly by industries. The other rivers (Chacha, Beresa and Jemma) belong to the Abay (Blue Nile) basin and are found at relatively high altitude (19002770m). Recently, few industries have been planted near these rivers, especially near Beresa and Chacha rivers which are releasing their waste to these rivers which is 
undoubtedly expected to affect the ecology of the rivers. Unlike the other rivers, Jemma River is less affected by industries. Therefore, it was our interest to assess the current ecological status of these rivers using benthic macroinvertebrate indicators along the gradient of the impact level (from potentially less impacted to severely impacted) and altitudinal gradient. invertebrate identification was done to family level using identification keys of Barbour et al (1995) and Bouchard (2012). Then, the abundance and percent composition of each family was determined for each sample by counting.

\section{Data Analysis}

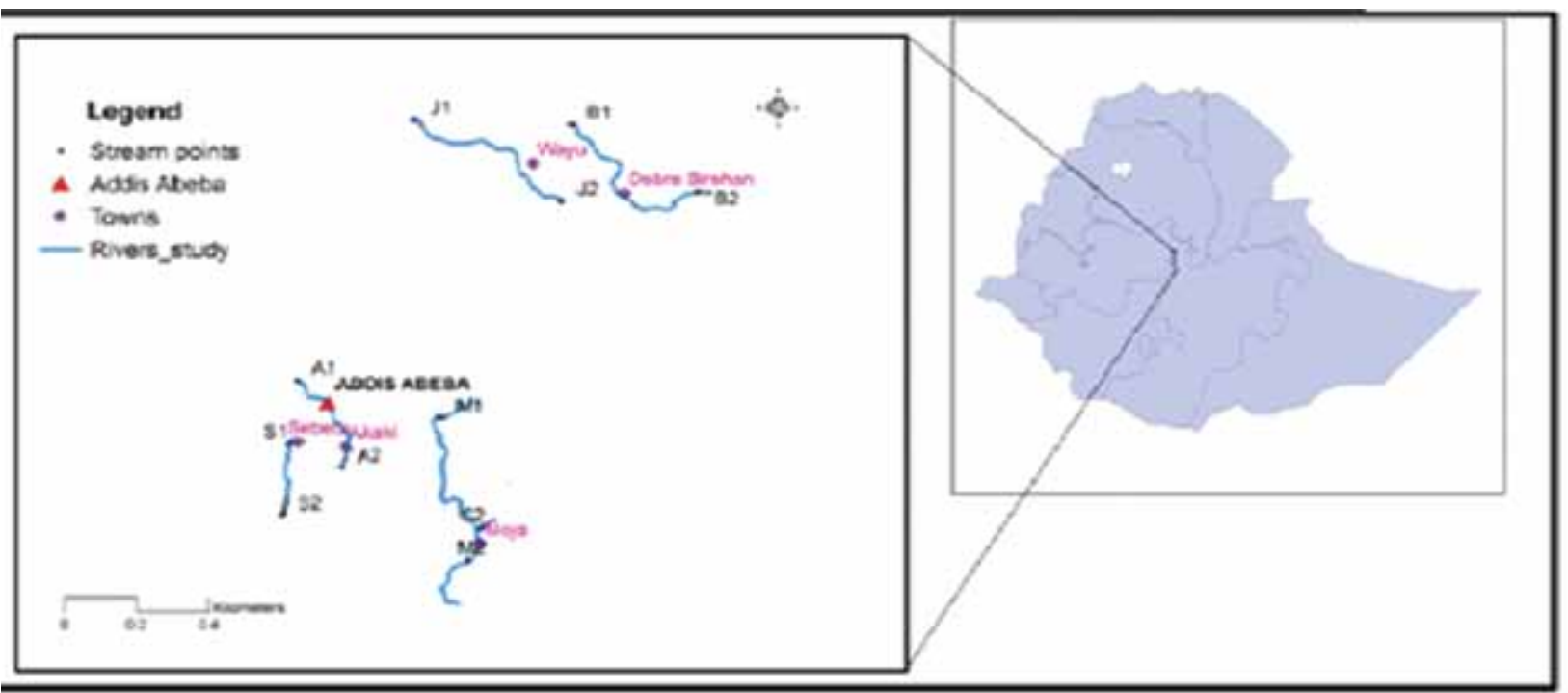

Figure 1: Map of the study sites (Abbreviations: B1- upstream Beresa, B2- downstream Beresa, C1- upstream Chacha, C2downstream chacha, M1-upstream Mojo, M2-down stream Mojo, A1- upstream Akaki , A2-downstream Akaki, S1-upstream Sebeta, S2-downstram Sebeta, J1- upstream Jemma and J2-downstream Jemma)

\section{Sampling}

\section{Physico-Chemical Sampling}

Temperature, $\mathrm{pH}$ and $\mathrm{DO}$ of the rivers were measured twice in each site using a portable Hanna (9024) digital pH meter between January and April 2015. One litter composite water samples (by integrating samples from spatial gradient) were collected in replicate from each site during each visit to analyse nitrate (NO3-), total phosphorus (TP) and soluble reactive phosphate (SRP).

\section{Macro Invertebrate Sampling}

One hundred meter reach lengths that consist both riffle and pool habitats were selected in each site of the rivers for macro invertebrate sampling (Bouchard, 2012) and each site was visited twice during the sampling period and two hours were spent during each visit. Two types of samplers were used depending on the habitats type. Surber sampler (with $0.5 \mathrm{~mm}$ mesh size) was used in riffle areas where there was fast flow of water; D frame net (with $0.5 \mathrm{~mm}$ mesh size) was used in pool areas. After sampling, the macroinvertebrates were separated from debris in situ and preserved in $70 \%$ ethanol and were then taken to the laboratory for identification.

\section{Laboratory Work}

The analysis of NO3-, SRP and TP was done monthly using spectrophotometric method. NO3-was analyzed with sodium salicylate method (APHA, 1995), and SRP and TP with ascorbic method (APHA, 1999). Macro

\section{Indices used for Data Analysis}

Shannon and Weiner (1963) index was used to assess the diversity of macroinvertebrates in these rivers. Hilsenhoff Family of Biotic Index (H-FBI) (Hilsenhoff, 1988) was calculated to assess the pollution tolerance of each collected taxa in each site as follows.

\section{$\mathrm{H}-\mathrm{FBI}=\Sigma\left(\mathrm{xi}^{*} \mathrm{ti}\right) /(\mathrm{n})$,}

Where, $\mathrm{xi}=$ number of individuals, $\mathrm{ti}=$ tolerance value, and $\mathrm{n}=$ total number of organisms in the sample. ti was obtained from the value given in Bouchard (2012) for each family of macroinvertebrates and ranges from o-10. Benthic Index of Biological Integrity (B-IBI) was used to assess the ecological status of the sites for this study purpose following the procedure of Barbour et al (1995) and Sitotaw (2006).

\section{Multivariate Analysis}

Multivariate analysis (Canonical Correspondence Analysis (CCA)) was used to study the association between macro invertebrate abundance and physicochemical factors using CANOCO 4.5 software. Principal component analysis (PCA) was used to observe how sites varied with respect to physico-chemical variables or to observe the physico-chemical gradient along the sites using PAST software as the relation was unconstrained (Ter Braak, 1987).

\section{Results}


Variation in Physico-Chemical Variables among the Study Sites

Analysis of physico-chemical variables showed wide variation among the study sites. DO was below $3 \mathrm{mg} / \mathrm{l}$ in both sites of Sebeta and Akaki River where as high DO measurements were recorded in Beresa and Chacha rivers (Table 1). Mean TP was the highest ( $45.63 \mathrm{mg} / \mathrm{l})$ in Akaki 2 sites and the next high value $(32.36 \mathrm{mg} / \mathrm{l})$ was recorded in the same river (Akaki1). TP was very low at both sites of Jemma River (0.2 and $0.9 \mathrm{mg} / \mathrm{l}$ ) and Chacha (particularly C2) River. Axis 1 and axis 2 of the PCA explained $68.3 \%$ of the total variance (Fig. 2) regarding the sites versus physico-chemical association, where the first axis and second axis contributed $44.5 \%$ and $23.8 \%$ to the variation, respectively. The result of the analysis discriminates Chacha, Beresa and Mojo (1) rivers (by axis 1) from other sites by having high $\mathrm{pH}, \mathrm{DO}$, and nitrate. Mojo (2) was highly associated with high SRP.

\begin{tabular}{|c|c|c|c|c|c|c|}
\hline \multicolumn{5}{|c|}{ Mojo (2) was highly associated with high SRP. } & \multicolumn{2}{|c|}{ Metrics Selectic } \\
\hline River & pH & $\begin{array}{c}\text { DO } \\
(\mathrm{mg} / \mathrm{I})\end{array}$ & $\begin{array}{c}\text { Temperature } \\
\text { (Oc) }\end{array}$ & $\begin{array}{c}\text { TP } \\
(\mathrm{mg} / \mathrm{I})\end{array}$ & $\begin{array}{c}\mathrm{NO}_{3}^{-} \\
{ }^{-}(\mathrm{mg} / \mathrm{I})\end{array}$ & $\mathrm{PO}_{4}^{-2}(\mathrm{mg} / \mathrm{I})$ \\
\hline B 1 & $9.01 \pm 0.5$ & $8.2 \pm 0.2$ & $15 \pm 0.3$ & $19.46 \pm 3$ & $2.73 \pm 0.9$ & $0.0182 \pm 0.01$ \\
\hline B 2 & $8.7 \pm 0.7$ & $8.5 \pm 0.4$ & $13 \pm 0.2$ & $25.06 \pm 2$ & $2.9 \pm 0.4$ & $0.81 \pm 0.05$ \\
\hline $\mathrm{C} 1$ & $9.0 \pm 0.3$ & $8.0 \pm 0.8$ & $14 \pm 0.4$ & $11.67 \pm 5$ & $5.02 \pm 0.3$ & $0.02 \pm 0.01$ \\
\hline $\mathrm{C} 2$ & $9.7 \pm 0.7$ & $9 \pm 0.4$ & $14 \pm 0.3$ & $1.03 \pm 3$ & $4.04 \pm 0.6$ & $0.0049 \pm 0.05$ \\
\hline M 1 & $9.1 \pm 0.8$ & $7.9 \pm 0.4$ & $20 \pm 0.5$ & $2.01 \pm 2$ & $0.45 \pm 0.5$ & $0.9 \pm 0.03$ \\
\hline M 2 & $9.4 \pm 0.6$ & $4.5 \pm 0.6$ & $24 \pm 0.3$ & $6.8 \pm 0.7$ & $0.33 \pm 0.3$ & $2.9 \pm 0.05$ \\
\hline $\mathrm{A} 1$ & $8.33 \pm 0.9$ & $2.7 \pm 0.5$ & $17.4 \pm 0.3$ & $32.63 \pm 3$ & $0.45 \pm 1$ & $0.0807 \pm 0.05$ \\
\hline A 2 & $8.6 \pm 0.8$ & $2.08 \pm 0.6$ & $19.4 \pm 0.5$ & $45.63 \pm 0.5$ & $1.08 \pm 0.2$ & $0.65 \pm 0.03$ \\
\hline $\mathrm{S} 1$ & $8.5 \pm 0.2$ & $2.00 \pm 0.5$ & $29 \pm 0.3$ & $3.9 \pm 0.1$ & $0.9 \pm 0.2$ & $0.56 \pm 0.05$ \\
\hline S2 & $8.41 \pm 0.6$ & $2.59 \pm 0.8$ & $34 \pm 0.7$ & $1.21 \pm 2$ & $0.39 \pm 0.5$ & $0.0145 \pm 0.05$ \\
\hline $\mathrm{J} 1$ & $8 \pm 0.9$ & $7.1 \pm 0.9$ & $21 \pm 0.2$ & $0.2 \pm 0.3$ & $0.20 \pm 0.2$ & $0.003 \pm 0.001$ \\
\hline $\mathrm{J} 2$ & $8.59 \pm 0.5$ & $6.71 \pm 0.5$ & $21.3 \pm 0.2$ & $0.94 \pm 0.5$ & $0.3 \pm 0.1$ & $0.017 \pm 0.005$ \\
\hline
\end{tabular}

Table 1: Physico-chemical variables in the study sites

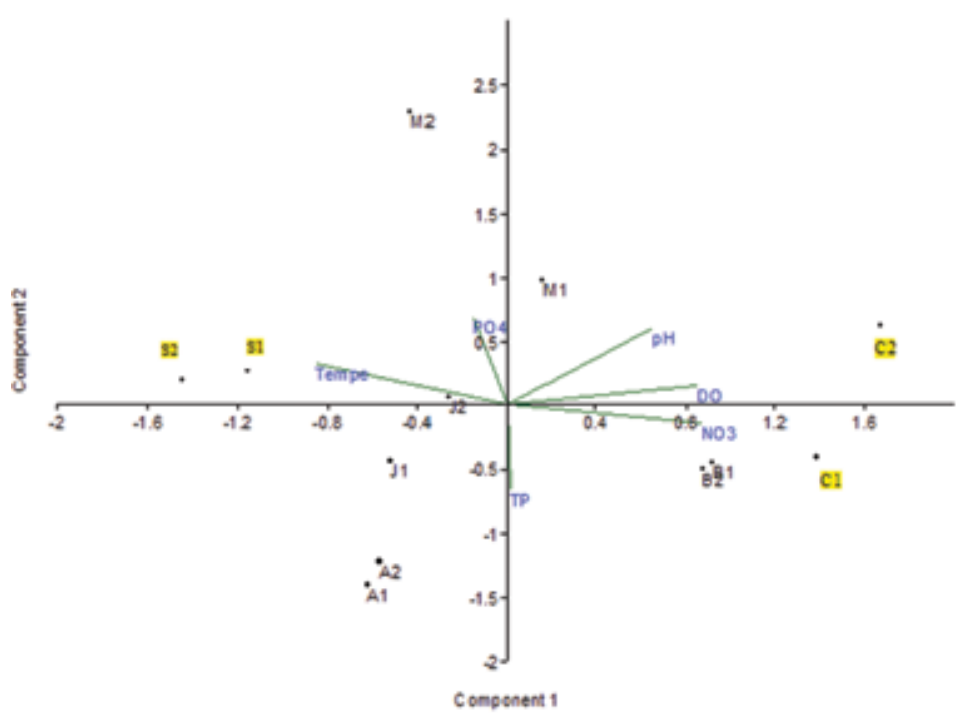

Figure 2: Principal components analysis ordination diagram of the physicochemical factors at study sites (Abbreviations: A1 - Akaki 1, A2 - Akaki 2, B1 - Beresa 1, B2 Beresa 2, C1 - Chacha 1, C2 - Chacha 2, S1 - Sebeta 1, S2 - Sebeta 2, M1 - Mojo 1, M2 - Mojo2, J1, Jemma1-J2 Jemma2; DO-Dissolved Oxygen, TP-Total Phosphorus, PO4- Soluble Reactive Phosphate, NO3, Nitrate, Temp-Temperature)

\section{Macro invertebrate Species Composition of the Rivers}

One thousand one hundred thirty three (1133) individuals of macroinvertebrates, belonging to 22 families and 5 orders of insects, were collected from the rivers. Diptera comprised the largest proportion in terms of total number of families sampled followed by non-insect and Ephemeroptera. Chironomidae (red) was the most abundant family (in terms of number) and occurred in all rivers. High number of Culicidae and Corixidae were also recorded next to Chironomidae, although their occurrence was restricted in Sebeta River (particularly Culicidae) and Beresa, Chacha and downstream of Mojo rivers (Corixidae). Ephemeropterans, which are commonly considered as indicator of good water quality, were entirely absent in Akaki, Sebeta and Jemma river.

\section{Metrics Selection}

Only seven metrics that had low correlation ( $p>0.05$ ) (Table 2) were selected to calculate the final B-IBI in each site, and others metric were eliminated as they have redundant information. \%EPT, \% Chironomidae and Hilsenhoff Family Biotic Index were eliminated as they had strong correlation $(\mathrm{p}<0.05, \mathrm{R} 2=0.86)$ with \% Ephemeroptera and \% Diptera and had redundant information (Table 2).

\section{B-IBI Determination for the} Sites

B-IBI value was calculated by adding the sum of the scores of the metrics, which were assigned into three categories $(5,3$ and 1$)$, and standardizing to 100 points (Table 3). Based on their B-IBI value, it can be seen that both sites of Akaki, Sebeta and Jemma rivers had poor water quality whereas Beresa, Chacha and Mojo (upstream site) had relatively better water quality (Table 3). There was no difference in the impairment level between downstream and upstream sites of Sebeta and Jemma rivers which were similarly impaired and had poor water quality. Both sites of Beresa River were moderately impaired and the status of water quality of the river was observed to be fair although the upstream site had lower B-IBI value. The downstream of Chacha and upstream of Mojo river were less impaired than other sites and have better ecological condition.

\section{Relationship between Macro Invertebrate Families and Physico- Chemical Variables \\ The first two axes of canonical}


correspondence analysis explained association of 53.3\% of families versus environmental variables and the correlation between the species and environment in the first and second axis was 0.95 and 0.907 , respectively. CCA showed that temperature was more strongly and positively correlated with Tabanidae, Syrphidae, Culicidae, Clams and Caenidae whereas it was strongly but negatively associated with Tricorythidae, Planorbidae, Heptageniidae, Simulidae, Sphaeriidae and Hydropysichdae (Fig. 3) . DO, $\mathrm{NO}_{3}$ - and $\mathrm{pH}$, on the other hand was strongly and positively correlated with Tricorythidae, Planorbidae, Heptageniidae, Simulidae, Sphaeridae and Hydropysichdae and negatively with Tabanidae, Syrphidae, Culicidae, Clams and Caenidae (Fig. 3). TP and SRP was more strongly correlated with Corixidae, Oligochaete, Heptageniidae, Simulidae, Sphaeridae but negatively with Clam, Caenidae and Tabanidae. Taxa such as Chironomidae (both red and pale) and Elmidae had poor correlation with the environmental variables measured in this study (Fig. 3). Relationship between the Metrics and Physico-Chemical Variables

\begin{tabular}{|c|l|l|l|l|l|l|l|l|l|l|}
\hline & \%TR & \%Eph & \% Bae & \% EPT & SW & \% Chi & \% Dipt & \% Olig & \%NI & HFBI \\
\hline \%TR & 1.00 & 0.150 & 0.296 & 0.212 & 0.296 & 0.113 & -0.086 & -0.254 & -0.468 & -0.392 \\
\hline \%Eph & 0.15 & 1.00 & 0.533 & 0.99 & 0.341 & -0.61 & -0.921 & -0.409 & 0.037 & -0.725 \\
\hline \% Bae & 0.29 & 0.53 & 1.00 & 0.485 & 0.055 & -0.229 & -0.44 & -0.024 & -0.409 & -0.293 \\
\hline \% EPT & 0.21 & 0.99 & 0.485 & 1.00 & 0.334 & -0.595 & -0.91 & -0.457 & 0.0075 & -0.783 \\
\hline SW & 0.296 & 0.34 & 0.055 & 0.33 & 1.00 & -0.039 & -0.466 & 0.0092 & 0.3450 & -0.382 \\
\hline \% Chi & 0.112 & -0.61 & -0.229 & -0.595 & -0.038 & 1.00 & 0.61 & 0.312 & -0.253 & 0.265 \\
\hline \% Dipt & -0.086 & -0.92 & -0.45 & -0.906 & -0.465 & 0.61 & 1.00 & 0.147 & -0.253 & 0.664 \\
\hline \% Olig & -0.254 & -0.41 & -0.024 & -0.456 & 0.009 & 0.312 & 0.15 & 1.000 & 0.466 & 0.385 \\
\hline \%NI & -0.47 & 0.038 & -0.41 & 0.007 & 0.345 & -0.253 & -0.25 & 0.466 & 1.00 & 0.131 \\
\hline HFBI & -0.392 & -0.73 & -0.29 & -0.783 & -0.382 & 0.266 & 0.66 & 0.385 & 0.131 & 1.00 \\
\hline
\end{tabular}

Table 2: Spearman Rank Order Correlations between the metrics (Underlined correlations are significant at $p<.05000)$

\begin{tabular}{|c|c|c|c|c|c|c|c|c|c|}
\hline Site & \%TR & \%Eph & \%Bae & SW & \%Dipt & \%Olig & \%NI & Total & BIBI \\
\hline B1 & 1 & 5 & 1 & 3 & 5 & 5 & 1 & 21 & 60 \\
\hline B2 & 1 & 3 & 1 & 3 & 5 & 5 & 5 & 23 & 65.7 \\
\hline C1 & 5 & 1 & 1 & 3 & 3 & 5 & 5 & 23 & 65.7 \\
\hline C 2 & 1 & 5 & 5 & 3 & 5 & 5 & 5 & 29 & 82.85 \\
\hline M 1 & 5 & 3 & 3 & 5 & 5 & 5 & 5 & 31 & 88.57 \\
\hline M 2 & 1 & 1 & 1 & 3 & 3 & 5 & 5 & 19 & 54.28 \\
\hline A1 & 1 & 1 & 1 & 3 & 1 & 3 & 3 & 13 & 37.14 \\
\hline A 2 & 1 & 1 & 1 & 3 & 3 & 1 & 1 & 11 & 31.42 \\
\hline S1 & 1 & 1 & 1 & 1 & 1 & 5 & 5 & 15 & 42.85 \\
\hline S 2 & 1 & 1 & 1 & 3 & 3 & 5 & 1 & 15 & 42.85 \\
\hline J 1 & 1 & 1 & 1 & 1 & 1 & 5 & 5 & 15 & 42.85 \\
\hline J 2 & 1 & 1 & 1 & 3 & 1 & 5 & 5 & 17 & 48.57 \\
\hline
\end{tabular}

Table 3: Standardized scores of each metrics in the sites

It was noted that $\mathrm{pH}$ was significantly $(\mathrm{p}<0.05$, R2=0.91) and positively correlated with \% Eph and \% Bae whereas DO with \% Ephemeroptera (Table 4). DO showed strong but negative correlation \% Oligo, \% NI and HFBI. Temperature was strongly and positively correlated with NI but negativity and significantly with \% Eph ( $\mathrm{p}<0.05, \mathrm{R} 2=0.9)$. TP, SRP and $\mathrm{NO}_{3}^{-}$ concentration showed positive correlation with most of the selected metric, except \% Dipt where it was negative for all the nutrient variables. However, the correlation was not statistically significant at $\mathrm{p}>0.05$.

\section{Discussion}

\section{Environmental Variables in the Rivers}

Beresa and Chacha rivers had higher DO than other sites of the rivers which agrees with the observation of Sitotaw (2006). High DO in these rivers indicated the presence of relatively low organic pollution compared to other sites of other rivers. DO is usually low in water where there is high organic input due to microbial respiration (Wetzel, 2001). Rivers of Akaki, Sebeta, Jemma and downstream of River Mojo had significantly lower DO and were dominated by Chironomidaes and other low oxygen tolerant families (e. g. Syrphidae larvae). This agreed with the observation of Visinskiene and Bernotiene (2012) who observed the abundance of these species in some European rivers with lower DO. The higher concentration of TP in Akaki River showed the presence of inorganic pollution in the river in addition to the organic pollution which most probably derived from the industries. This condition, with other factors not realized in this study, seemed to restrict the distribution of macroinvertebrate community to species that tolerate inorganic contamination (e.g. Chironomidae).

\section{Relationship between Macro- invertebrate Families and Environmental Variables}

The strong correlation between the species and environment in the first (0.95) and second (0.907) axis in CCA showed that these axes had strong predictive power on the selected environmental parameters. It can be inferred from the analysis that families such as Tabanidae, Syrphidae, Culicidae, Clams and Caenidae seem to prefer high water temperature and do well in water with low $\mathrm{pH}$, DO and nitrate level. The observation agreed to some extent with the result of Knee and Encalada (2014). Thus, such families could be considered as indicator of high temperature and lower levels of $\mathrm{pH}, \mathrm{DO}$ and nitrate.

Tricorythidae, Planorbidae, Heptageniidae, Simulidae, Sphaeridae and Hydropysichdae showed the reverse trend. They showed strong negative correlation with temperature but strong and positive correlation with $\mathrm{pH}, \mathrm{DO}$ and nitrate level. It implied that these families 
could be indicators of higher $\mathrm{pH}, \mathrm{DO}$ and nitrate level. As the CCA analysis showed that all types of chironomidae sampled in this study seem to have poor correlation with the environmental variables which indicated that they are poor indicators of environmental conditions. In fact, this observation agree with the report of Beneberu (2013) who stated that Chironomidae cannot be considered as indicator macroinvertebrates at family level unless their taxonomic resolution is done to lower taxonomic level.



Figure 3. Biplot of canonical correspondence analysis (CCA) (Abbreviations: Baet-Baetidae, Hydrop- Hydrophilidae, Tric-, Tricorythidae,Plano- Planorbidae, Elmi- Elmidae, Sciom- Sciomyzidae, Turb-Turbilaria, Chir(Pa)-Chironomidae Pale, Chir(red)-Chironomidae red, Oligo-Oligochaeta, Corix-Corixidae, Hept-Heptagniidae, SphaeSphaeridae, Simu-Simulidae, Philo- Philopotamidae, Cae- Caenidae , Taban-Tabanidae, Syrph-Syrphidae, Culic-Culicidae; DO-Dissolved Oxygen, TP-Total Phosphorus, PO4- Soluble Reactive Phosphate, NO3 Nitrate, Temp-Temperature)

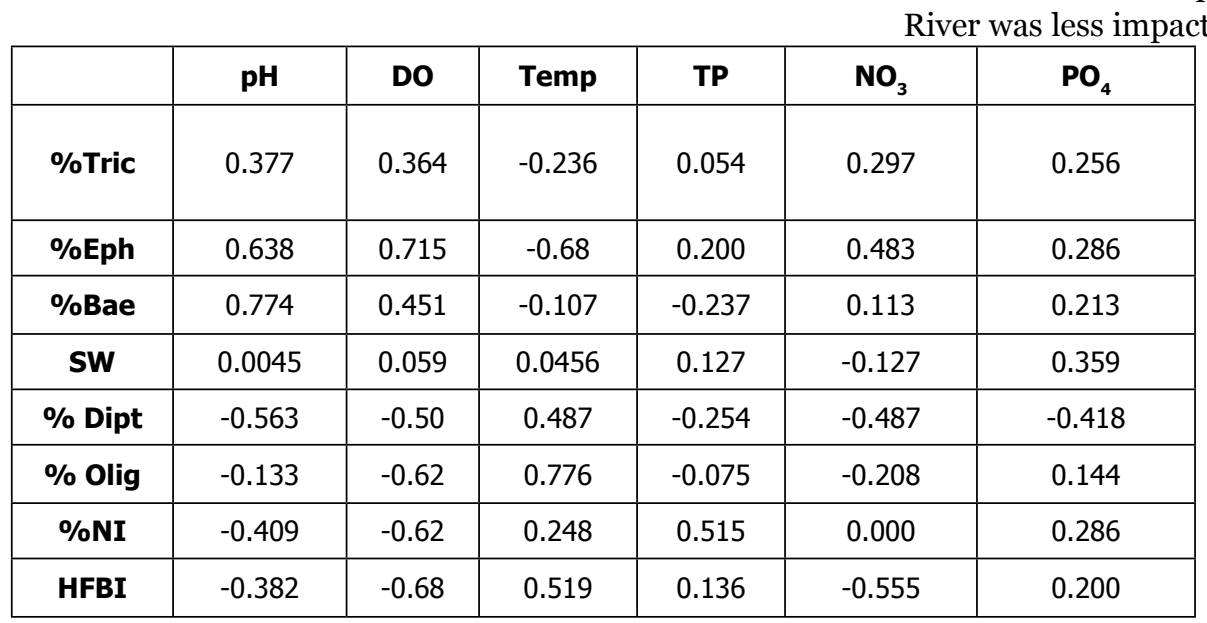

Table 4: Spearman Rank Order Correlations between the metrics and environmental variables (Marked correlations are significant at $p<0.05$ )

\section{Association between the Metrics and Environmental Variables}

TP, SRP and NO3- concentration showed positive correlation with most of the selected metric, except \% Dipt where it was negative for all the nutrient variables, although it was statistically not significant ( $p>0.050$ ). It implies that these metrics may not be important indicators when used solely to indicate the inorganic nutrient status of the water. However, correlation between TP and NI were strong which agrees with observation Sitotaw (2006). Thus, percentage of noninsect macroinvertebrate could be used as an indicator for total phosphorus enrichment. \% Eph and \% Bae were strongly and positively associated with high $\mathrm{pH}$ which implied that high $\mathrm{pH}$, upto certain level, could favour the dominance of these families. \% Eph was also strongly and positively associated with DO. It entailed that high

\% Eph could indicate high DO in such systems which in turn means that there is low organic input in such water which agrees with the observation of Klemm et al (2003) and Arimoro and Muller (2010). \% Olig, \% NI and HFBI were negatively but strongly correlated with DO.

\section{Classification of Sites Using B-IBI}

B-IBI showed that water quality of both sites of River Akaki, Sebeta and Jemma were poor and impaired while sites of Beresa 1, Beresa 2, Chacha 1, Mojo 2 were impacted moderately. Akaki and Sebeta were obviously impacted by the industries found at the vicinities of the river. B-IBI values of Downstream of Chacha and upstream Mojo indicated that these sites were the least impacted of all other sites and were found in relatively good condition. The B-IBI values of both sites of Beresa were categorized under moderate impairment, although the upstream site had relatively high B-IBI value as compared to the downstream site of the same river. The enrichment from the university campus and textile could be responsible for the high B-IBI value of this particular site. Although Beresa River was less impacted than Akaki and Sebeta rivers at present, it is highly likely that the ecology of the river will be impaired severely as the volume of waste released to the river from these sites could increase with the expansion of the university and industrial activities around the river.

Girum Tamire holds BSc in Biology from Bahir Dar University (2002), MSc in fisheries and Aquatic Sciences from Addis Ababa Natural Sciences, Department of Biology (2006) and PhD in fisheries and Aquatic Sciences from Addis Ababa University, Natural Sciences, Department of Biology (2014). He has published in co-author number of papers.

Coresponding E-mail: tamiregirum1@gmail.com 
Gezahegn Degefe obtained BED in Biology from Alemaya University (2000-2003), MSc in Ecological and Systematic Zoology from Addis Ababa University (2005-2006) and PhD in Ecological and Systematic Zoology from Addis Ababa University (2009-2013). He has published in co-author number of papers.

Seid Mohammed Hassen holds BSc Degree in Biology in 2009 MSc in Genetics from Addis Ababa University in2013. Since 2015, he is studying PhD in Osnabrueck University, Germany.

Abinet Haile holds BSc Degree in Chemistry from Mekele University in 2005 and MSc in Genetics from Addis Ababa University in 2007. Since 2013, he is studying PhD in Addis Ababa University, Ethiopia

\section{Reference}

APHA (American Public Health Associations), 1995, Standard methods for the examination of water and wastewater, 19th edn. American Public health Association, Washington, DC, USA.

APHA (American Public Health Associations), 1999, Standard methods for the examination of water and wastewater, 20th edition, American Public Health Association, New York, NY.

Arimoro, F.O., Muller, W.J., 2010, Mayfly (Insecta: Ephemeroptera) community structure as an indicator of the ecological status of a stream in the Niger Delta area of Nigeria. Environmental Monitoring Assessment,166:581-594.

Barbour, M.T., Stribling, J.B., Karr, J.R., 1995, Multimetric approach for establishing biocriteria and measuring biological condition, in: Biological assessment and criteria. Tools for water resource planning and decision making, pp 63-76 (Davis, W.S. and Simon, T.P., eds.) CRC LLC press. Boca Raton, Florida.

Beneberu G., 2013, The family Chironomidae (Insecta: Diptera) as indicators of environmental stress, and macro-invertebrate based multimetric index development in some selected rivers in Ethiopia. $\mathrm{PhD}$ Dissertation, Addis Ababa University, Addis Ababa, Ethiopia.

Bouchard, W., 2012, Guide to Aquatic Invertebrate Families of Mongolia, Saint Paul, Minnesota, 222pp

Davis, B.R. and Day, J.A. 1998. Vanishing Waters. University of Cape Town Press.

Eshetu, F. 2012. Physico-chemical pollution pattern in Akaki River Basin. Addis Ababa, Ethiopia, MSc, Stockholm University, Sweden.
Hilsenhoff, W.L. 1988. Rapid field assessment of organic pollution with a family level biotic index. J. North Am. Benthol. Soc. 7(1): 65-68.

Karr, J.R. and Chu, E.W. 1999. Restoring Life in Running Waters: Better Biological Mon-itoring. Island Press, Washington, DC.

Knee, K. L. and Encalada, A. C. 2013. Land use and water quality in a rural cloud forest region (Intag, Ecuador). River research and application, 3:385-401.

Klemm, D.J., Blocksom,K.A., Fulk, F.A., Herlihy,A.T., Hughes, R.M., Kaufmann,P.R., Peck, D.V., Stoddard, J.L., Thoeny, W.T., Griffith, M.B., and Davis, W.S, 2003. Development and evaluation of a macroinvertebrate biotic integrity index (MBII) for regionally assessing Mid-Atlantic Highlands Streams. Environ. Manage. 31:656-669.

Morse, J. C., Bae, Y. J., Munkhjargal, G., Sangpradub, N., Tanida, K. Tatyana S. V., Wang, B., Yang, L. and Yule C.M., 2007. Freshwater Biomonitoring with Macroinvertebrates in East Asia. Frontiers in Ecology and the Environment. 1: 33-42 .

Pawlak, B., 1999. The basics of bio assessment: reference conditions. Virginia Lakes and Watersheds Association Newsletter 48: 8-9.

Shannon, C.E. and Weiner, W. 1963. The Mathematical Theory of Communication. University of Illinois Press, Urbana, IL, 117pp.

Sitotaw, B., 2006, Assessment of BenthicMacroinvertebrate structures in relation to Physicochemical parameters. MSc thesis, Addis Ababa University, 145pp.

Ter Braak, C.J.E., 1987, The analysis of vegetationenvironment relationships bycanonical correspondence analysis. Vegetatio, 69:69-77.

Valentina, S., Momir, P., Branko, M. Vasil, K., Milica, R. and Donka, M. 2011. WaterQuality Assessment Based on the Macroinvertebrate Fauna - the Pcinja River Case Study. Water Research and Management, 1: 63-69.

Velho, L.F.M., Pereira, D.G., Pagioro, T. A., Santos, V.D., Perenha, M.C.Z. and Lansactôha, F.A. 2005. Abundance, biomass and size structure of planktonic ciliates in reservoirs with distinct trophic states. Acta Limnologica Brasiliensia, 17(4):361-371.

Visinskiene, G. and Bernotiene, R., 2012. The use of benthic macroinvertebrate families for river quality assessment in Lithuania. Central European Journal of Biology, 7(4): 741-758

Wetzel, R.G. 2001, Limnology: Lake and River Ecosystems. Academic Press, U.S.A. 